\title{
Jornada de trabalho docente e o cumprimento da Lei do Piso \\ nas capitais ${ }^{1}$
}

Teachers' working time and the accomplishment of the Base Salary Law in the capitals Jornada de trabajo docente y el cumplimiento de la Ley del Suelo en las capitales

\section{MÁRCIA APARECIDA JACOMINI JUCA GIL EDIMÁRIA CARVALHO DE CASTRO}

\begin{abstract}
Resumo: Neste artigo analisamos a duração e a composição das jornadas de trabalho do professor da Educação Básica das capitais. O objetivo é saber se a Lei $\mathrm{n}^{\circ} 11.738 / 2008$ estava sendo cumprida, em 2016. no aspecto relativo à composição da jornada de trabalho Trata-se de pesquisa documental e bibliográfica, com base na legislação sobre planos de carreira e na literatura acadêmica sobre o tema. Verificamos que havia grande diversidade na duração e na composição da jornada dos professores e que a maioria das capitais não cumpria a Lei do Piso. Por outro lado, em algumas capitais o percentual da jornada destinado às atividades de apoio à docência ultrapassava $1 / 3$, mínimo estabelecido na Lei de 2008.
\end{abstract}

Palavras-chave: Trabalho Docente; Jornada de Trabalho; Educação Básica; Lei do Piso.

\begin{abstract}
In this article, we analyze the duration and the composition of the teachers' working time in the capitals' basic education. The aims are to know if Law \# 11.738 / 2008 was being enforced in the aspect related to the composition of the working time, in 2016. It is a documental study and a bibliographic research, based on the legislation on career plans and in the academic literature on the theme. We verified that there was great diversity in the duration and composition of the teachers' working time and that most capitals did not comply with the Base Salary Law. On the other hand, in some capitals, the percentage of the time working allocated to teaching support activities exceeded $1 / 3$, minimum established in the Law of 2008.
\end{abstract}

Keywords: teaching work; working time; basic education; Base Salary Law.

Resumen: En este artículo analizamos la duración y la composición de las jornadas de trabajo del profesor de la educación básica de las capitales. El objetivo es saber si la Ley $n^{\circ} 11.738$ / 2008 se estaba cumpliendo en el aspecto relativo a la composición de la jornada de trabajo, en 2016. Se trata de investigación documental y bibliográfica, con base en la legislación sobre planes de carrera y 
en la literatura académica sobre el tema. Verificamos que había gran diversidad en la duración y en la composición de la jornada de los profesores y que la mayoría de las capitales no cumplía la Ley del Suelo. Por otro lado, en algunas capitales el porcentaje de la jornada destinado a las actividades de apoyo a la docencia superó el 1/3, mínimo establecido en la Ley de 2008.

Palabras clave: Trabajo Docente; Jornada de trabajo; Educación básica; Ley del Suelo.

\section{INTRODUÇÃO}

O tema da duração e composição da jornada de trabalho do professor da escola pública tem permeado o debate sobre as condições de docência e os embates entre sindicatos e poder público acerca de qual seria a jornada de trabalho adequada, considerando-se as especificidades e/ou particularidades do trabalho educativo.

Argumenta-se que o trabalho docente, por envolver uma relação entre sujeitos, requer mais que um profissional com conhecimentos específicos sobre o que ensinar, mas um profissional capaz de provocar situações de aprendizagem. Isso demanda intenso envolvimento do professor com o "objeto" de trabalho, no caso, um ser humano em desenvolvimento, num espaço privilegiado de aprendizagem e formação, a escola.

Além das especificidades que caracterizam o trabalho do professor e que condicionam sua luta por uma jornada de trabalho adequada, o professor também participa da luta mais ampla dos trabalhadores pela diminuição da duração da jornada de trabalho, diminuição esta que lhe permitiria dedicar-se a outras atividades fundamentais ao bem-estar, além da sobrevivência, como a convivência familiar e social, ao lazer, ao estudo etc.

Com o processo de organização da escolarização da sociedade brasileira durante o século XX, e da institucionalização da escola graduada (SOUZA, 1998), a jornada de trabalho do professor, especialmente a do professor primário, esteve vinculada às horas de aula, fazendo com que sua jornada de trabalho coincidisse com a jornada de estudo do aluno, normalmente, um período de três ou quatro horas diárias.

Essa condição, mais característica da primeira metade do século XX, contribuiu para o mito de que a docência é profissão de mulheres porque admite jornada parcial de trabalho e permite, assim, combinar o trabalho doméstico e o cuidado dos filhos com uma atividade remunerada, mito que segundo Souza (2008) não se sustenta nos dias atuais à medida que a jornada de trabalho docente 
da maioria das professoras não é parcial. Alves e Pinto (2011) verificaram que 67,6\% dos docentes da Educação Básica possuíam jornada de trabalho semanal de 26 horas ou mais, em 2009.

De acordo com estudos de Monlevade (2000) e Cação (2001), o que ocorreu, especialmente na segunda metade do século XX, foi um processo de aumento da jornada de trabalho do professor em função dos baixos salários. Se do ponto de vista coletivo o poder aquisitivo foi enfrentado por meio de lutas, quase sempre traduzidas em greves, do ponto de vista individual, os professores foram obrigados a aumentar a jornada de trabalho, possibilitando, assim, a recomposição parcial dos salários.

De uma situação em que a antiga professora primária lecionava durante o período da manhã ou da tarde, e no período inverso preparava aula e corrigia as atividades dos alunos, passou-se à extensão da jornada, com os professores trabalhando em dois ou até três períodos, devido ao funcionamento das escolas no período noturno.

Essa condição comprometeu o trabalho que o professor realizava fora da sala de aula, muitas vezes sem o recebimento pecuniário por ele, posto que além das horas em sala de aula o poder público pagava algumas poucas horas-atividades para a realização do trabalho de apoio à docência.

Criou-se, portanto, uma situação em que a duração da jornada do professor tornou-se muito extensa, e cuja composição quase desconsiderava que nesta profissão apenas parte do trabalho é realizada em sala de aula. Para cada hora em sala de aula, o professor trabalha mais um quantum de horas não mensuradas, tornando-se difícil quantificar quantas horas de fato ele trabalha, já que o tempo de trabalho se estende para além da sala de aula e permeia parte da vida privada (SOUZA, 2008).

Esse é o contexto sob o qual se desenvolveram as reivindicações e as lutas pela diminuição do tempo de trabalho e por uma composição da jornada que considere tanto as horas em sala de aula quanto aquelas dedicadas às atividades de apoio à docência.

De uma realidade em que as horas-atividades correspondiam na maioria das vezes a no máximo $20 \%$ do total da jornada, passando pela posição da Confederação Nacional dos Trabalhadores em Educação (CNTE) que reivindica uma composição 50\% para atividades de interação com os alunos e 50\% para as atividades de apoio à docência, chegou-se a uma política pública, com a Lei do Piso de 2008 (BRASIL, 2008), que estabelece no máximo 2/3 da jornada do professor da Educação Básica para atividades de interação direta com os alunos. 
Assim, do ponto de vista nacional, apenas na primeira década do século XXI, por meio de uma lei federal, as atividades de apoio à docência foram consideradas parte da jornada do professor na proporção de 1/3. Antes disso, cabia à legislação estadual ou municipal disciplinar a questão.

E foi somente em 2011, com a publicação do Acórdão do Supremo Tribunal Federal (STF) (BRASIL, 2011), que se reconheceu a constitucionalidade da Lei $\mathrm{n}^{\mathrm{o}} 11.738 / 2008$ na íntegra, tornando obrigatório aos entes federados o cumprimento da Lei, a partir de 27 de abril de 2011. Contudo, a jornada de trabalho docente com o mínimo de $1 / 3$ destinado às atividades de apoio à docência ainda não é realidade em muitas redes de ensino. Por isso, estudos que informam em que medida a Lei do Piso está sendo cumprida pelos governos municipais em relação à composição da jornada, são importantes para que a sociedade, especialmente a parte diretamente envolvida, possa acompanhar e cobrar o cumprimento da Lei.

Neste texto são apresentadas as jornadas de trabalho e respectivas composições das redes públicas de ensino dos municípios das capitais dos 26 estados brasileiros, com base no que está previsto nos planos de carreira ou legislação concernente, em vigor até o ano de 2016. Trata-se de pesquisa documental e bibliográfica, sendo os planos de carreira municipais e a legislação nacional que trata da valorização docente os principais documentos. Os planos de carreira foram analisados nos aspectos referentes à duração e à composição das jornadas de trabalho. Em relação à pesquisa bibliográfica dialogou-se com a literatura que tem discutido a especificidade do trabalho docente e as condições de trabalho, especialmente nos aspectos relacionados à jornada.

O texto é composto por três partes além desta introdução. Na primeira, apresenta-se um diálogo com a literatura e se estabelecem os marcos sobre a especificidade e particularidade do trabalho docente para se pensar a duração e a composição da jornada de trabalho. Na segunda, são apresentados e analisados os dados sobre jornada de trabalho nas redes públicas dos municípios das capitais dos estados brasileiros. Por último, discute-se como uma jornada adequada em termos de duração e composição pode contribuir para melhorar as condições de trabalho do professor e, potencialmente, repercutir positivamente na qualidade do ensino.

\section{TRABALHO DOCENTE E JORNADA DO PROFESSOR DA EDUCAÇÃO BÁSICA}

Alguns autores têm discutido em que medida tem adentrado o espaço escolar a proletarização, característica do trabalho no sistema capitalista, especialmente na fábrica, em que há divisão clara entre quem concebe e quem 
executa o trabalho. Um texto interessante sobre essa temática é o de Ozga e Lawn (1991) no qual os autores avaliam de forma crítica trabalho anterior, no sentido de apresentar um conjunto de questionamentos à ideia de proletarização do professor que haviam defendido. Com base em Braverman (1974), os autores definiram proletarização como sendo

O processo que resulta quando o trabalhador é privado da capacidade para ao mesmo tempo planejar e executar o trabalho, isto é, a separação entre concepção e execução, e a divisão da execução em partes separadas, controláveis, simples. Este processo desqualifica o trabalhador, e resulta na erosão da autonomia no local de trabalho, na ruptura de relações entre trabalhadores e empregadores, no declínio da habilidade do ofício, e no aumento dos controles administrativos. (OZGA, LAWN, 1991, p. 142)

Ao retomar a discussão de forma crítica, os autores chamam a atenção para a importância de se estudar o trabalho docente tendo em vista aspectos relacionados às experiências, às ações coletivas, às culturas (OZGA, LAWN, 1991), ou seja, advertem que colocar o trabalho do professor dentro do esquema geral de proletarização significa desconsiderar as contradições presentes no exercício de ensinar. Por isso, defendem no referido trabalho que é necessário desconstruir a ideia de proletarização do professor e, principalmente, compreender esta ideia como algo que deve ser contestado.

Apple e Teitelbaun (1991) também analisam em que medida o professor está perdendo controle do seu trabalho, e concluem que isso está acontecendo no que concerne ao currículo, mas destacam que, apesar das limitações na autonomia que os professores vêm sofrendo em relação à escolha dos materiais curriculares, não se pode dizer que não há qualquer autonomia e que exista separação efetiva entre concepção e execução no trabalho do professor.

Também Enguita (1991) discute a questão da proletarização do professor e sustenta que a docência encerra certa ambiguidade, o que coloca o profissional do ensino entre o que ele chama de profissionalismo e proletarização, ou seja, para o autor, há no trabalho docente elementos de ambos.

Não é foco deste texto discutir a questão da proletarização do professor; a referência a essa questão deve-se ao fato de ela circunscrever especificidades do trabalho do professor que permitem pensar a jornada de trabalho docente em termos de duração e composição.

Pode o professor, no exercício da docência, ser alijado do controle sobre os meios, os objetivos e o processo de seu trabalho? Sustentamos que não. Se isso vier a acontecer estaremos diante de um novo modelo e prática de trabalho educativo. 
Primeiramente, é importante esclarecer que há controle sobre o trabalho do professor no sentido de que ele está inserido num sistema que estabelece regras e normas sobre o que e como ensinar; portanto, a autonomia do professor é relativa. Em termos gerais, há que se cumprir a Lei de Diretrizes e Bases da Educação Nacional (LDB), as Diretrizes e os Parâmetros Curriculares Nacionais (DCNs e PCNs) e, atualmente, a implementação da recém aprovada Base Nacional Comum Curricular (BNCC). A essas podem ser agregadas normativas estaduais e municipais.

A intensidade e abrangência do controle externo do trabalho docente depende, em certa medida, das políticas educacionais. Nos últimos tempos, podese dizer que este controle tem-se fortalecido à medida que as avaliações externas condicionam os conteúdos que devem ser privilegiados pelo professor e pela escola. Também colabora para diminuir a autonomia do professor a adoção de ensino apostilado, cujo caráter diretivo diminui o espaço para o professor atuar como planejador e executor do processo de ensino e de aprendizagem. E se enfocarmos as condições de autonomia docente nas escolas privadas é provável que as ações de proprietários e pais de alunos aportem outras restrições.

Contudo, por mais controle que as redes de ensino estabeleçam sobre o trabalho do professor, este não se assemelha ao que ocorre na produção fabril em que a separação entre concepção e execução e a divisão do trabalho em partes leva o trabalhador a não ter qualquer controle sobre o processo de produção.

Entre o conteúdo e a metodologia de ensino estabelecidos nos livros didáticos, nas apostilas ou em qualquer outro material que orientam o trabalho do professor existem dois sujeitos que dão vida ao processo educativo e que impossibilitam um controle total do ato de ensinar e aprender por parte de qualquer instância externa à escola. Há um espaço de criação, que marca a especificidade de cada professor na relação com os estudantes que não pode ser controlado pelo Estado por meio de materiais didáticos, apostilas etc.

Isso ocorre porque, para se ensinar é preciso que o estudante queira aprender; portanto, não se trata de ministrar aulas, no sentido do mestre explicador criticado por Rancière (2005), mas de colocar em jogo inteligência e vontade do aluno e do professor.

Se para executar o trabalho na fábrica não é necessário que o trabalhador tenha vontade de estar ali, tampouco precisa convencer seu objeto de trabalho a tomar a forma pensada por quem concebeu o produto; na escola, ocorre exatamente o oposto. Por mais preciso e interessante que seja o material didático a ser utilizado pelo professor, se não houver uma atuação deste profissional no sentido de fazer a mediação entre o conhecimento sistematizado e o momento 
de aprendizagem do aluno, tendo em conta a condição de sujeito de ambos, não haverá aprendizagem nem, consequentemente ensino. Nas palavras de Vitor Paro (2015, p. 66).

O professor é necessariamente sujeito porque tem um objetivo a realizar e se aplica a sua realização; o educando é sujeito porque o êxito do aprendizado só se dá se ele aplica sua vontade na atividade de aprender. Além disso, o educando, como objeto de trabalho - ou seja, o elemento do processo de trabalho que se transforma (em sua personalidade viva) no produto final (o indivíduo educado) por meio da apropriação da cultura - precisa ser sujeito (o ser humano-histórico). Como, numa ação eficiente, os meios não podem contrariar os fins, o objeto de trabalho pedagógico não pode ser mero objeto, mas um sujeito, mesma condição esperada do produto que se propõe a realizar.

E nisso consiste a especificidade e particularidade do trabalho do professor que, se assim realizado, the garante certo controle sobre os meios, os objetivos e o próprio processo de seu trabalho.

Em que pese o fato de as políticas educacionais pouco contribuírem para que essas características do processo educativo sejam realizadas em sua inteireza, há que se ter em conta, ao se analisar o trabalho docente, as resistências individuais e coletivas, as culturas e as experiências que se desenvolvem no cotidiano da escola e que dão ao processo educativo e ao trabalho do professor um caráter único, que une, em certa medida, concepção e execução, no marco dos procedimentos comuns da atividade docente.

Assim, pode-se considerar que existe indução das políticas públicas educacionais para que o professor siga uma série de orientações acerca do quê e do como ensinar, que é em maior ou menor grau seguida. A competência do professor, entendida como o conhecimento e capacidade específicos que ele tem para exercer a docência, que o diferencia dos demais e lhe concede estatuto profissional, é aspecto fundamental para a autonomia didático-pedagógica. Quanto melhor preparado estiver o professor para exercer a profissão e quanto melhores forem as condições que ele tiver para desenvolver seu trabalho individual e coletivamente, melhor poderá realizar a atividade educativa, mais criativo será no trato com o currículo e os métodos de ensino formulados nas esferas das instituições do Estado hierarquicamente superior à escola.

Há um círculo vicioso alimentado pelas políticas educacionais que precisa ser rompido se se deseja melhorar a qualidade da educação e valorizar o magistério público, conforme tem sido explicitado na legislação nacional. A formação inicial e, por vezes, a continuada dos professores nem sempre têm contribuído para um sólido conhecimento da área. Diante disso, as políticas educacionais se voltam mais ao treinamento, para o desenvolvimento de determinadas tarefas, e ao 
estabelecimento do quê e do como ensinar de forma cada vez mais sistemática e sistematizada, e menos ao investimento em uma formação que contemple os diferentes conhecimentos que o exercício da profissão docente requer. Reforçase assim o ciclo. Diante de professores, cuja formação não lhes possibilita maior autonomia didático-pedagógica, o Estado, por meio das políticas públicas, formula manuais que, se seguidos, pretensamente melhorariam a qualidade do ensino e, consequentemente, da aprendizagem, o que não tem ocorrido.

Como o trabalho do professor não se resume a técnicas de ensino, mas à criação de um ambiente de ensino e aprendizagem, a simples aplicação de técnicas não resulta na melhoria da aprendizagem. Chama-se atenção aqui para o papel do professor, para a diferença que um professor bem formado e em condições adequadas de trabalho pode fazer em termos de qualidade do ensino.

A ação docente exige capacidade de planejar a intervenção pedagógica para determinado grupo de alunos, adequar sua atuação às necessidades e conhecimentos daqueles indivíduos, de construir relações naquele coletivo; de se dedicar à leitura, interpretação e correção das tarefas daqueles estudantes em específico, alterar rotas com base em seus achados, estudar, buscar informações e alternativas. É preciso tempo para o necessário contato com os pais, tendo em vista o melhor atendimento das necessidades e especificidades dos alunos. A educação dos estudantes de determinada escola também é um trabalho que demanda ação coletiva, que deve ser realizada pela atuação do conjunto dos professores e isso exige que eles tenham tempo para refletir e planejar suas ações na perspectiva do coletivo escolar. Enfim, o trabalho do professor não é, de modo algum, mecânico, ele exige dedicação e isso requer tempo em sua jornada profissional, além das horas destinadas às atividades em sala de aula.

A partir dessas reflexões sobre especificidade e particularidade do trabalho docente serão apresentadas, no próximo tópico, a duração e a composição das jornadas de trabalho de professores da Educação Básica das redes públicas de ensino dos municípios das capitais do Brasil, tendo em vista o pressuposto de que uma jornada de trabalho adequada poderia contribuir positivamente para a qualidade da educação escolar.

\section{DURAÇÃO E COMPOSIÇÃO DA JORNADA DE TRABALHO DO PROFESSOR DE EDUCAÇÃO BÁSICA NAS REDES DE ENSINO DAS CAPITAIS}

Com o objetivo de averiguar se as redes de ensino públicas dos municípios das capitais estavam cumprindo legalmente a proporção de $2 / 3$, no máximo, da jornada de trabalho do professor para atividades de interação com os estudantes, 
conforme estabelece a Lei do Piso, realizamos levantamento das informações sobre jornadas de trabalho nos planos de carreira desses entes federados, com base na legislação em vigor no ano de 2016.

Consideramos que, após oito anos da aprovação da Lei no 11.738/2008 (Lei do Piso) (BRASIL, 2008) e seis do reconhecimento de sua constitucionalidade pelo Supremo Tribunal Federal, seria importante saber se nos planos de carreira em vigor no ano de 2016, estava prevista a composição da jornada conforme a Lei do Piso.

Assim, para conhecer quais capitais destinavam, ao menos, $1 / 3$ da duração da jornada de trabalho dos professores da Educação Básica das redes públicas municipais às atividades de apoio à docência, procedemos ao levantamento das jornadas previstas nos planos, em termos de duração e composição, conforme apresentado na Tabela 1 .

Tabela 1 - Duração e composição das jornadas de trabalho dos professores da educação básica das redes públicas municipais das capitais -2016

\begin{tabular}{|c|c|c|c|}
\hline Capital & $\begin{array}{l}\text { Jornadas (em horas } \\
\text { semanais) }\end{array}$ & $\begin{array}{l}\text { Composição das Jornadas } \\
\text { Carga horária da jornada (horas de interação } \\
\text { com alunos + horas sem interação com } \\
\text { alunos) }\end{array}$ & $\begin{array}{l}\text { Cumpre a lei do } \\
\text { Piso? }\end{array}$ \\
\hline Rio Branco & 25 & $25(20+5)$ & Não \\
\hline Maceió & $20 ; 25 ; 40$ & $20(15+5) 25(19+6) 40(30+10)$ & Não \\
\hline Manaus & $20 ; 40$ & $20(12+8) 40(20+20)$ & $\operatorname{Sim}$ \\
\hline Macapá & $20 ; 40$ & $20(12+8) 40(24+16)$ & $\operatorname{Sim}$ \\
\hline Salvador & $20 ; 40$ & $20(13+7) 40(26+14)$ & $\operatorname{Sim}$ \\
\hline Fortaleza & 40 & $40(32+8)$ & Não \\
\hline Vitória & $25 ; 25 ; 40 ; 40$ & $25(20+5) 25(19+6) 40(32+8) 40(30+10)$ & Não \\
\hline Goiânia & $20 ; 40 ; 60$ & $20(14+6) 40(28+12) 60(42+18)$ & Não \\
\hline São Luís & $20 ; 24 ; 40$ & $20(16+4) 24(19+5) 40(32+8)$ & Não \\
\hline $\begin{array}{c}\text { Belo } \\
\text { Horizonte }\end{array}$ & $22 \mathrm{~h} 30$ & $22 \mathrm{~h} 30(17 \mathrm{~h} 30+5)$ & Não \\
\hline $\begin{array}{l}\text { Campo } \\
\text { Grande }\end{array}$ & $20 ; 40$ & $20(16+4) 40(32+8)$ & Não \\
\hline Cuiabá & 20 & $20(16+4)$ & Não \\
\hline Belém & $20 ; 24 ; 30 ; 40 ; 48$ & $\begin{array}{c}20(16+4) 24(19+5) 30(24+6) 40(32+8) 48 \\
(38+10)\end{array}$ & Não \\
\hline $\begin{array}{l}\text { João } \\
\text { Pessoa }\end{array}$ & $25 ; 30$ & $25(20+5) 30(20+10)$ & Parcialmente \\
\hline Recife & $145 ; 270 ; 290 ; 415^{\star}$ & $145(125+20) 270(250+20) 290(270+20)$ & Não \\
\hline Teresina & $20 ; 40$ & $20(13+7) 40(26+14)$ & Sim \\
\hline
\end{tabular}




\section{Tabela 1 - Duração e composição das jornadas de trabalho dos professores da educação básica das redes públicas municipais das capitais -2016}

\begin{tabular}{|c|c|c|c|}
\hline Capital & $\begin{array}{l}\text { Jornadas (em horas } \\
\text { semanais) }\end{array}$ & $\begin{array}{l}\text { Composição das Jornadas } \\
\text { Carga horária da jornada (horas de interação } \\
\text { com alunos + horas sem interação com } \\
\text { alunos) }\end{array}$ & $\begin{array}{l}\text { Cumpre a lei do } \\
\text { Piso? }\end{array}$ \\
\hline Curitiba & 20 & $20(16+4)$ & Não \\
\hline $\begin{array}{l}\text { Rio de } \\
\text { Janeiro }\end{array}$ & $22 \mathrm{~h} 30 ; 40 ; 16 ; 30 ; 40$ & $\begin{array}{c}22 \mathrm{~h} 30(15+7 \mathrm{~h} 30) 40(26+14) 16(10+6) 30 \\
(20+10) 40(26+14)\end{array}$ & Sim \\
\hline Natal & $20 ; 40$ & $20(16+4) 40(32+8)$ & Não \\
\hline Porto Velho & $20 ; 25 ; 30 ; 40$ & $20(15+5) 25(20+5) 30(20+10) 40(22+18)$ & Parcialmente \\
\hline Boa Vista & 25 & $25(16+9)$ & Sim \\
\hline Porto Alegre & 20 & $20(12 \mathrm{~h} 30+7 \mathrm{~h} 30) 20(20+4$ mensais $)$ & Parcialmente \\
\hline Florianópolis & $20 ; 40$ & $20(13+7) 40(26+14)$ & Sim \\
\hline Aracajú & $25 ; 32 ; 40 ; 40$ & $25(13+12) 32(20+12) 40(20+20) 40(30+10)$ & Parcialmente \\
\hline São Paulo & $25 ; 30 ; 40$ & $25(20+5) 30(25+5) 40(25+15)$ & Parcialmente \\
\hline Palmas & $20 ; 40$ & $20(16+4) 40(32+8)$ & Não \\
\hline $\begin{array}{l}\text { Campo } \\
\text { Grande }\end{array}$ & $20 ; 40$ & $20(16+4) 40(32+8)$ & Não \\
\hline Cuiabá & 20 & $20(16+4)$ & Não \\
\hline Belém & $20 ; 24 ; 30 ; 40 ; 48$ & $\begin{array}{c}20(16+4) 24(19+5) 30(24+6) 40(32+8) \quad 48 \\
(38+10)\end{array}$ & Não \\
\hline João Pessoa & $25 ; 30$ & $25(20+5) 30(20+10)$ & Parcialmente \\
\hline Recife & $145 ; 270 ; 290 ; 415^{*}$ & $145(125+20) 270(250+20) 290(270+20)$ & Não \\
\hline Teresina & $20 ; 40$ & $20(13+7) 40(26+14)$ & Sim \\
\hline
\end{tabular}

Fonte: Rio Branco (2012), Maceió (2005), Manaus (2007), Macapá (2009), Salvador (2015), Fortaleza (2007), Vitória (2006), Goiânia (2000), São Luís (2008), Belo Horizonte (1998), Campo Grande (2008), Cuiabá (2010), Belém (1991), João Pessoa (2012), Recife (2004), Teresina (2013), Curitiba (2007), Rio de Janeiro (capital) (2013), Natal (2010), Porto Velho (2009), Boa Vista (2015), Porto Alegre (1988,2004), Florianópolis (2012), Aracajú (2001), São Paulo (Capital) (2007), Palmas (2006). Porto Alegre: O cumprimento da jornada de 20 horas é diferenciado para professor de Ensino Fundamental e Médio e professor de Educação Infantil. No caso deste último, são 20 horas semanais de interação com os alunos e quatro horas mensais para atividades de trabalho coletivo na escola. Também são destinados três dias no início e três no final do ano letivo para atividades de planejamento aos professores de Educação Infantil.

2 "Parcialmente" significa que em algumas das jornadas previstas no referido plano de carreira o percentual de horas sem interação com os estudantes não atinge o critério de $33 \%$ da carga horária. 
Em relação à duração da jornada, observa-se grande diversidade nas capitais, conforme já apontava trabalho de Gil, Trein e Wolker (2016). Há dez diferentes jornadas semanais, em termos da quantidade de horas (16, 20, 22h30, 24, 25, 30, 32, 40, 48 e 60). Diferentemente das demais, em Recife a jornada é mensal (145, 270, 290 e 415 horas) respectivamente.

Apesar da grande quantidade de jornadas, na maior parte dos planos de carreira das capitais (10) estão previstas duas jornadas (Manaus, Macapá, Salvador, Vitória, Campo Grande, João Pessoa, Teresina, Natal, Florianópolis e Palmas). Em sete planos está prevista uma única jornada (Rio Branco, Fortaleza, Belo Horizonte, Cuiabá, Curitiba, Boa Vista e Porto Alegre). Já em cinco municípios estão previstas três jornadas (Maceió, Goiânia, São Luís, Aracajú e São Paulo), enquanto em outros três planos constam quatro jornadas (Recife, Rio de Janeiro e Porto Velho) e em um só plano figuram cinco jornadas (Belém).

No que tange à frequência em que cada carga horária de jornada de trabalho figurada nos planos de carreira evidenciamos que as 40 horas semanais são as mais comuns, constando em 18 municípios (69\%). A segunda com mais menções é a de 20 horas semanais, aparecendo em 16 municípios (61\%). Em 8 municípios consta a jornada de 25 horas semanais (31\%) e em 5 cidades figura a jornada de 30 horas semanais (19\%). As jornadas de 24 horas semanais e de $22 \mathrm{~h} 30$ são mencionadas, cada qual, em 2 municípios. As demais possibilidades de jornadas ocorrem em apenas um município cada.

Diante dessa diversidade, pode-se inferir que os professores das redes públicas de ensino das capitais trabalham em diferentes jornadas. Chama a atenção a jornada de 60 horas semanais prevista no plano de carreira de Goiânia, duração que fere o previsto na Constituição Federal de 1988 (CF/88) (BRASIL, 1988). Em São Paulo (capital) também foi encontrada no plano de carreira a possibilidade de o professor trabalhar mais de 44 horas semanais, quando em acúmulo de cargo. De acordo com estudo de Arelaro et al (2014), na rede municipal de São Paulo o professor pode trabalhar até 70 horas semanais.

O professor é um dos profissionais que pode acumular cargos, de acordo com o artigo $7^{\circ} \mathrm{da} \mathrm{CF} / 88$, portanto, pode-se inferir, inclusive devido aos baixos salários, que muitos professores, quando em jornada de tempo parcial, trabalham em outra rede de ensino ou na mesma acumulando dois ou mais cargos.

Por isso, é importante que os entes federados invistam no estabelecimento de jornadas de trabalho de tempo integral, com ao menos $1 / 3$ destinada às atividades de apoio à docência, de forma que o professor possa atuar numa única rede de ensino, preferencialmente, na mesma escola, conforme propõe a Resolução no 2 do CNE/CEB (BRASIL, 2009). 
Somente sete capitais cumprem o limite máximo de $2 / 3$ do tempo em interação com estudantes para todas as jornadas (Manaus, Macapá, Salvador, Boa Vista, Florianópolis, Teresina e Rio de Janeiro) e cinco cumprem parcialmente, ou seja, não aplicam a proporção máxima de $2 / 3$ para todas as jornadas (São Paulo, João Pessoa, Porto Velho, Porto Alegre e Aracajú).

Considerando que a Lei do Piso é de 2008, e que em 2011 o Supremo Tribunal Federal reconheceu sua constitucionalidade, determinando que os entes federados cumprissem a legislação em sua integralidade, é notável que, em 2016, menos da metade das capitais previa para todas as jornadas a proporção máxima de $2 / 3$ de interação com estudantes nos respectivos planos de carreira.

Esse descumprimento da Lei do Piso, no que se refere à composição da jornada tem implicações nas condições de trabalho do professor e, potencialmente, na qualidade do ensino. Portanto, o cumprimento da Lei diz respeito não somente aos direitos trabalhistas do professor, mas à educação de qualidade a que todo estudante tem direito.

Diante do não cumprimento da Lei do Piso, pela maioria das capitais, procedemos à verificação do percentual de cada jornada destinado às atividades de apoio à docência, conforme Quadro 1 .

\section{Quadro 1- Percentual destinado às atividades de apoio à docência dos professores da Educação Básica das redes públicas municipais das capitais}

\begin{tabular}{|c|c|}
\hline Capital & Percentual das jornadas destinadas às atividades de apoio à docência \\
\hline Rio Branco & $20 \%$ \\
\hline Maceió & $25 \%$ (jornada de 20$), 24 \%(25), 25 \%(40)$ \\
\hline Manaus & $40 \%$ (jornada de 20), 50\% (40) \\
\hline Macapá & $40 \%$ \\
\hline Salvador & $35 \%$ (jornada de 20), 35\% (40) \\
\hline Fortaleza & $20 \%$ \\
\hline Vitória & $20 \%$ e 24\% (jornada de 25), 20\% e 25\% (40) \\
\hline Goiânia & $30 \%$ \\
\hline São Luís & $20 \%$ \\
\hline Belo Horizonte & $23 \%$ \\
\hline Campo Grande & $20 \%$ \\
\hline Cuiabá & $20 \%$ \\
\hline Belém & $20 \%$ \\
\hline João Pessoa & $20 \%$ (jornada de 25), 33\% (30) \\
\hline Recife & $1 \%$ para jornada de 145), 0,8\% (250), 0,7\% (290) \\
\hline
\end{tabular}




\section{Quadro 1- Percentual destinado às atividades de apoio à docência dos professores da Educação Básica das redes públicas municipais das capitais}

\begin{tabular}{|c|c|}
\hline Capital & Percentual das jornadas destinadas às atividades de apoio à docência \\
\hline Teresina & $35 \%$ \\
\hline Curitiba & $20 \%$ \\
\hline Rio de Janeiro & $33 \%$ (jornada de $22 \mathrm{~h} 30), 35 \%(40), 33 \%(30) 37 \%(16)$ \\
\hline Natal & $20 \%$ \\
\hline Porto Velho & $25 \%$ (jornada de 20$), 20 \%(25), 33 \%(30), 45 \%(40)$ \\
\hline Boa Vista & $36 \%$ \\
\hline Porto Alegre & $37 \%(20) 0 \%(20)$ \\
\hline Florianópolis & $35 \%$ \\
\hline Aracajú & $48 \%$ (jornada de 25$), 37,5 \%(32), 50 \%$ e $25 \%($ jornadas de 40$)$ \\
\hline São Paulo & $33 \%$ (jornada de 40$), 20 \%(25), 17 \%(30)$ \\
\hline Palmas & $20 \%$ \\
\hline
\end{tabular}

Fonte: Elaborado com base na legislação citada na Tabela 1.

De acordo com as informações do Quadro 1, os planos ${ }^{3}$ de quatro capitais (São Paulo, João Pessoa, Porto Velho, Rio de Janeiro) contemplavam jornadas com a composição de $1 / 3$ para atividades de apoio à docência, mínimo previsto na Lei do Piso. Além dessas capitais, cujos planos preveem jornadas com o percentual mínimo estabelecido para atividades de apoio à docência, há aqueles que apresentavam, em seus planos, jornadas com percentuais acima de $1 / 3$ para as atividades de apoio à docência. Esses percentuais variaram de 35\% a 50\%. Entre eles estão: Florianópolis, Teresina, Boa Vista, Porto Velho, Aracajú, Rio de Janeiro, Manaus, São Paulo e Porto Alegre.

É interessante observar que em nove planos há percentual acima do mínimo previsto na Lei do Piso para as atividades de apoio à docência. Mas, é necessário destacar que o percentual de $50 \%$ é somente para a jornada de 40 horas semanais em Manaus, por exemplo.

Não obstante esses avanços, nos planos de carreira de 17 capitais há percentuais da jornada destinados às atividades de apoio à docência que variam entre 20\% e 30\% (Rio Branco, Maceió, Fortaleza, Vitória, Goiânia, São Luís, Belo Horizonte, Campo Grande, Cuiabá, Belém, Natal, Curitiba, João Pessoa,

3 Como um mesmo plano tem mais de uma jornada e composições diferenciadas para mesma jornada, os números apresentados não correspondem ao número de capitais. 
Porto Velho, Aracajú, Palmas, São Paulo). Além dos percentuais abaixo de 20\% numa das jornadas da capital paulista e os baixíssimos percentuais das jornadas de Recife.

Apesar de na Lei do Piso a jornada de referência ser a de 40 horas semanais, entende-se que o percentual máximo de $2 / 3$ para interação com estudantes deve ser aplicado a todas as jornadas, independentemente da duração e da etapa da educação na qual o professor trabalha. Trata-se de uma compreensão de que o trabalho do professor se estende além da sala de aula e isso independe da quantidade de aulas que ele ministra semanalmente ou etapa de ensino que leciona. Conquanto, não foi isso que encontramos em todos os planos. Em 10 planos há percentuais de horas para atividades de apoio à docência diferentes para as diversas jornadas.

Nesses casos, há tendência de o percentual para as horas de apoio à docência aumentar para as jornadas de tempo integral, isto é, jornadas de 30 horas ou mais. Em Porto Alegre, embora a duração da jornada dos professores de Ensino Fundamental e Médio seja igual à do professor de Educação Infantil (20 horas), a composição é bastante diferente: enquanto os primeiros trabalham 12 horas e 30 minutos com os alunos, os professores de Educação Infantil trabalham as 20 horas em sala de aula, quatro horas diárias.

A legislação nacional não define o local onde deve ser cumprida a parte da jornada de trabalho sem interação com estudantes. De acordo com os planos de carreira ela é realizada na escola e/ou em local de livre escolha. As atividades de formação, de elaboração e execução coletiva do Projeto Político Pedagógico, reunião com pais e responsáveis pelos estudantes são, necessariamente, realizadas na escola; as de preparo de aula, avaliações e atividades, correção de atividades e provas podem ser realizadas em local de livre escolha do professor.

Com o intuito de saber como é cumprida a parte da jornada destinada às atividades de apoio à docência, independentemente do cumprimento da Lei do Piso, procedemos ao levantamento, também com base na legislação dos planos de carreira, da parte que é cumprida na escola e daquela que é cumprida em local de livre escolha. Essa informação foi encontrada em poucos planos de carreira, indicando que se trata de assunto definido em legislação específica, como portarias, por exemplo, ou que elas não estão disciplinadas.

Essa informação foi encontrada em apenas sete planos das capitais. Em São Paulo, Porto Alegre e Boa Vista a maior parte das horas da jornada destinada às atividades de apoio à docência era cumprida na escola, em Campo Grande, Salvador, Aracajú e Natal as horas eram partilhadas igualmente, metade na escola e metade em local de livre escolha. 
Assim, na maioria dos planos, o número de horas cumprido na escola e em local de livre escolha era igual. Considera-se que, dada a importância do trabalho coletivo para o desenvolvimento do processo educativo, seria adequado estabelecer, especialmente, nos casos em que pelos menos $1 / 3$ da jornada é destinado às atividades de apoio à docência, que um número maior dessas horas fosse realizado na escola. Evidentemente, isso pressupõe a organização da escola para as atividades coletivas e de formação continuada tendo em vista que a permanência do professor na escola, além das horas em sala de aula, seja efetivamente direcionada ao desenvolvimento de um trabalho educativo de melhor qualidade. Nesse caso, salas de reuniões, bibliotecas e outros espaços precisariam estar disponíveis para a efetivação adequada dessas atividades.

Em relação ao incentivo à dedicação exclusiva, conforme proposto na Resolução no 2, do CNE/CEB de 2009 (BRASIL, 2009), os dados desta pesquisa indicam que as capitais estão bastante distantes de contemplar em seus planos a dedicação exclusiva como forma de estabelecer uma única jornada de trabalho ao professor e fixá-lo numa única rede de ensino e escola. Em três planos das capitais (Rio Branco, Maceió, Macapá) há referência à dedicação exclusiva de diferentes formas. Em alguns casos, a regulamentação da dedicação exclusiva é remetida a legislação específica. Em outros, a entrada no regime de dedicação exclusiva não se dá por opção do professor, mas por solicitação do poder público. Entre os planos que estabelecem acréscimo ao vencimento base, pelo regime de dedicação exclusiva, encontram-se os de Rio Branco, cujo percentual sobre o vencimento base para dedicação exclusiva é de 100\%; de Macapá com percentual de 55\% e de Natal com acréscimo de 50\% para o professor de educação infantil que optar pelo regime de dedicação exclusiva.

\section{ALGUMAS CONSIDERAÇÕES PARA FINALIZAR}

Discutimos neste artigo que o trabalho docente requer uma jornada de trabalho que contemple horas destinadas à atividade de interação com os estudantes e horas destinadas às atividades de apoio à docência, numa proporção de no máximo $2 / 3$ de atividades com os estudantes, conforme estabelecido na Lei do Piso. Também em relação à duração, é preciso considerar que se trata de uma atividade que exige intenso envolvimento com os educandos, o que requer grande dispêndio de energia; portanto, não deve ser muito longa.

Entrementes, o que encontramos ao analisar os planos de carreira das capitais foi o descumprimento, na maioria dos planos, dessa proporção na composição da jornada. Ou seja, a despeito dos avanços que a Lei do Piso trouxe em relação à composição da jornada, nas leis municipais ela não está 
sendo cumprida na maioria daqueles entes federados que estariam em melhores condições para fazê-lo (as capitais), se comparados aos demais municípios do país (que são, no geral, mais pobres economicamente).

Do ponto de vista das políticas educacionais, isso representa um problema e uma preocupação. Um problema porque, ao não se melhorarem as condições de trabalho do professor, não se criam melhores condições para a realização do processo educativo, o que compromete o direito dos estudantes a uma educação de boa qualidade. Uma preocupação porque se, mesmo sendo lei, as capitais não a cumprem, como estabelecer parâmetros nacionais de condições de trabalhos aos professores da Educação Básica?

As dificuldades orçamentárias de as capitais cumprirem a Lei do Piso, seja em relação ao valor mínimo do vencimento base estabelecido, seja em relação à composição da jornada, deveriam ser superadas com a ajuda da União, conforme estabelecido na Lei no 11.738/2008 (BRASIL, 2008). No entanto, há empecilhos normativos que inviabilizam o acesso ao apoio federal por estados que, por exemplo, estejam excluídos da complementação da União ao Fundeb. Posto que o piso salarial e a composição da jornada constituem elementos fundamentais para se começar a reverter a desvalorização profissional do professor, o cumprimento da Lei do Piso é premente.

No que se refere à jornada de trabalho do professor, as políticas de valorização docente devem considerar: duração e composição da jornada, acúmulo de cargo, dedicação exclusiva e trabalho numa única escola.

A Lei do Piso e a Resolução nº 2 do CNE/CEB de 2009 (BRASIL, 2009) estabelecem parâmetros sobre os quais os entes federados podem encaminhar a reformulação dos planos de carreira, com vistas à implantação de jornada única, de no máximo 40 horas semanais, com o mínimo de $1 / 3$ para as atividades de apoio à docência e incentivo à dedicação exclusiva. Isso poderia contribuir para profissionalização do professor, com repercussões positivas nas condições de trabalho e na qualidade do ensino.

Consideramos que a Lei do Piso, no que se refere ao estabelecimento da composição da jornada, significou um avanço em relação à situação anterior, em que não havia qualquer parâmetro em âmbito nacional para induzir os entes federados a garantirem um percentual da jornada para as atividades de apoio à docência. Entretanto, os dados desta pesquisa denunciam que a Lei não está sendo cumprida na maioria das capitais, comprometendo, dessa forma, o potencial da legislação de propiciar melhores condições de trabalho ao professor e melhores condições de ensino aos estudantes. Conjunturalmente, políticas macroeconômicas de ajuste fiscal vêm pressionando gestores públicos a cortarem gastos e direitos dos servidores, como a reforma trabalhista, a Emenda Constitucional $n^{\circ} 95$ 
(Teto de Gastos) e a proposta de reforma da previdência, as quais podem afetar a manutenção das atuais condições de docência e, ainda, reduzir ou prejudicar os patamares já alcançados.

\section{REFERÊNCIAS}

ALVES, Thiago. PINTO, José Marcelino de Rezende. Remuneração e características do trabalho docente no Brasil: um aporte. Cadernos de Pesquisa. v. 41, n. 143 Maio/Ago. p. 606-639, 2011.

APPLE. Michael W.; TEITELBAUN, Kenneth. Está o professor perdendo o controle de suas qualificações e do currículo? Teoria \& Educação. Dossiê: Interpretando o Trabalho Docente. Porto Alegre, n. 4, p. 62-73, 1991.

ARACAJU. Lei $\mathbf{n}^{\mathbf{0}} \mathbf{5 1}$ de 28 de dezembro de 2001. Disponível em: < http://www. aracaju.se.gov.br/legislacao/> e <file:///C:/Users/Pord/Downloads/lei\%20 51\%20de \%202001\%20Plano\%20de \%20Carreira\%20(3).pdf>. Acesso em: 06/01/2017.

ARELARO, Lisete Regina Gomes; JACOMINI, Márcia Aparecida; SOUZA, Nilson Alves de; SANTOS, Kátia Aparecida. Condições do trabalho docente: uma análise da carreira na rede municipal de ensino de São Paulo. Revista Brasileira de Estudos Pedagógicos. Brasília, v. 95, n.239, jan./abr., p. 197-217, 2014.

BELÉM. Lei No 7.528 de 05 de agosto de 1991. Disponível em: <http://cmbelem.jusbrasil.com.br/legislacao/586098/lei-7528-9>. Acesso em: 06/01/2017

BELO HORIZONTE. Lei No 7.577, de 21 de setembro de 1998. Disponível em: <http://cm-belo-horizonte.jusbrasil.com.br/legislacao/237420/lei-757798>. Acesso em 06/01/2017.

BOA VISTA. Lei $\mathbf{N}^{\mathbf{o}}$ 1.611, de 02 de fevereiro de 2015. Disponível em: $\quad<$ http://www.boavista.rr.gov.br/comum/code/MostrarArquivo. php?C=MTEwMw\%2C\%2C>. Acesso em: 08/01/2017.

BRASIL. SUPREMO TRIBUNAL FEDERAL. Ação Direta de Inconstitucionalidade 4.167. Brasília: STF: 2011. Disponível em: $<$ http:/ / redir. stf.jus.br/paginadorpub/paginador.jsp?docTP $=$ AC\&docID $=626497>\quad$ Acesso em: 26/08/2016. 
- Conselho Nacional de Educação. Câmara da Educação Básica. Resolução no 2, de 28 de maio de 2009. Disponível em: < http:/ / portal.mec.gov. br/dmdocuments/resolucao_cne_ceb002_2009.pdf> Acesso em: 30/01/2017.

Lei $\mathbf{n}^{\mathbf{0}}$ 11.738, de 16 de julho de 2008. Disponível em: <http://www. planalto.gov.br/ccivil_03/_ato2007-2010/2008/lei/111738.htm> Acesso em: $25 / 01 / 2017$.

Constituição da República Federativa do Brasil de 1988. Brasília, DF, 1988. Disponível em: < http://www.planalto.gov.br/ccivil_03/Constituicao/ Constituicao.htm>.Acesso em: 25/01/2017.

BRASÍLIA (DF). Lei $\mathbf{n}^{\mathbf{0}} \mathbf{5 1 0 5}$ de 03 de maio de 2013. Disponível em: < http:/ / legislacao.cl.df.gov.br/Legislacao/consultaTextoLeiParaNormaJuridicaNJ UR-271677!buscarTextoLeiParaNormaJuridicaNJUR.action>. Acesso em: 05/01/2017.

BRAVERMAN, Harry. Trabalho e capital monopolista: a degradação do trabalho no século XX. $3^{\text {a }}$ ed. Traduzido da primeira edição, publicada em 1974 por Monthly Review Press, de Nova York, Estados Unidos, 1974. Rio de Janeiro: LTC, 1987.

CAÇÃO, Maria Izaura. Jornada de trabalho docente: delineamento histórico da organização do trabalho do magistério público estadual paulista. 2001, 218p. Tese (Doutorado em Educação). Universidade Estadual de Campinas Campinas, 2001.

CAMPO GRANDE. Decreto 10.343 de 22 de janeiro de 2008. Disponível em: $\quad<$ http://torreseducacional.com.br/wp-content/uploads/2016/01/LeiComplementar-n.-19.pdf>. Acesso em: 06/01/2017.

CONFEDERAÇÃO NACIONAL DE TRABALHADORES EM EDUCAÇÃO (CNTE). Piso e carreira andam juntos para valorizar os profissionais da educação básica pública. Disponível em: http://www.cnte.org.br/images/ stories/publicacoes/cartilha_piso_e_carreira_andam_juntos.pdf Acesso em 19/12/2016.

CUIABÁ. Lei Complementar No 220 DE 22 de Dezembro de 2010. Disponível em: <http://lmc.cuiaba.mt.gov.br/mostrar-documento-publico?codigo=1807>. Acesso em: 06/01/2017. 
CURITIBA.Lei12.348deagostode2007.Disponívelem:<http://www.cmc.pr.gov. $\mathrm{br} / \mathrm{wspl} /$ sistema/BibLegVerForm.do?select_action=\&popup=s\&chamado_ por_link\&nor_id=13271\&pesquisa=>. Acesso em: 07/01/2017.

ENGUITA, Mariano Fernández. A ambiguidade da docência: entre a profissionalização e a proletarização. Teoria \& Educação. Dossiê: Interpretando o Trabalho Docente. Porto Alegre, n. 4, p. 41-61,1991.

FLORIANÓPOLIS. Lei Complementar $\mathbf{n}^{\mathbf{0}}$ 427, de 04 de abril de 2012. Disponível em: <https://leismunicipais.com.br/a/sc/f/florianopolis/ leicomplementar/2012/42/427/lei-complementar-n-427-2012-altera-a-lei-n2517-de-1986-a-lei-n-2915-de-1988-e-o-anexo-i-da-lei-n-7674-de-2008-e-daoutras-providencias>. Acesso em: 05/01/2017.

FORTALEZA. Lei $\mathbf{n}^{\mathbf{0}} \mathbf{9 2 4 9}$ de 10 de julho de 2007. Disponível em: <http:// pt.slideshare.net/guestd2e6b04/pccs-educao-pmf-lei-9249-de-10-de-2007>. Acesso em: 05/01/2017.

GIL, Juca; TREIN, Laura Dexheimer; WOLKER, Luiz Celso Sá Fronckowiak. Planos de carreira docente no Brasil: uma análise das jornadas de trabalho e sua composição nas redes estaduais de ensino a partir da lei no $11.738 / 08$. $4^{\mathbf{o}}$ Encontro Fineduca, Anais..., p. 995-1009, 2016. Disponível em: +https:// www.dropbox.com/s/mzcfirjcxwxyv2m/Anais\%202017.pdf?dl=0 Acesso em: 23/02/ 2017.

GOIÂNIA. Lei Complementar $\mathbf{n}^{\mathbf{0}} \mathbf{9 1}$ de 26 de junho de 2000. Disponível em: <https://www.goiania.go.gov.br/html/gabinete_civil/sileg/dados/legis/2000/ lc_20000626_000000091.html>. Acesso em: 05/01/2017.

JOAO PESSOA. Lei complementar 073 de julho de 2012. Disponível em: <http://177.200.32.195:9673/sapl/consultas/norma_juridica/norma_juridica_ mostrar_proc?cod_norma $=15437>$. Acesso em: 047/01/2017.

MACAPÁ. Lei $\mathbf{n}^{\mathbf{0}} \mathbf{0 6 5}$ de 31 de outubro de 2009. Disponível em: < https://drive. google.com/w?id=0B5XfqHsoLmPdUk5aOGlOSVJuaTA\&usp=sharing\&tid= 0B5XfqHsoLmPdSXpCZ1E1M3lzRUU>. Acesso em 05/01/2017. 
MACEIÓ. Lei $\mathbf{n}^{\mathbf{0}} \mathbf{5 4 9 0}$ de 29 de dezembro de 2005. Disponível em: <http:// www.camarademaceio.al.gov.br/legislacao/5503_anexo.pdf $>$. Acesso em: 05/01/2017.

MANAUS. Lei $\mathbf{n}^{\mathbf{0}} 1126$ de 5 de junho de 2007. Disponível em: <https:// leismunicipais.com.br/a/am/m/manaus/lei-ordinaria/2007/113/1126/ lei-ordinaria-n-1126-2007-dispoe-sobre-o-plano-de-cargos-carreiras-esubsidios-dos-profissionais-do-magisterio-do-municipio-e-adota-outras-providencias?q=Lei\%201.126>. Acesso em: 06/01/2017.

MONLEVADE, João Antônio Cabral de. Valorização salarial dos professores: o papel do Piso Salarial Profissional Nacional como instrumento de valorização dos professores da Educação Básica pública. 2000. 307p. Tese (Doutorado em Educação) - Universidade Estadual de Campinas, Campinas, 2000.

NATAL. Lei Complementar $\mathrm{n}^{\circ} 114$ de 17 de junho de 2010. Disponível em:<http://www.natal.rn.gov.br/_anexos/publicacao/legislacao/ LeiComplementar20100617_114.pdf>. Acesso em: 07/01/2017.

OZGA, Jenny; LAWN, Martin. O trabalho docente: interpretando o processo de trabalho do ensino. Teoria \& Educação. Dossiê: Interpretando o Trabalho Docente. Porto Alegre, n. 4, p. 140-158, 1991.

PALMAS. Lei $\mathbf{n}^{\circ}$ 1445, de 14 de agosto de 2006. Disponível em: <http:// legislativo.palmas.to.gov.br/media/leis/LEI\%20ORDIN\%C3\%81RIA\%20 N\%C2\%BA\%201445\%20de \%2014-08-2006\%2011-18-6.pdf>. Acesso em: 06/01/2017.

PARO, Vitor Henrique. Diretor Escolar: educador ou gerente? São Paulo: Cortez, 2015.

PORTO ALEGRE. Lei no 6.151, de 13 de julho de 1988. Disponível em: < https:/ / leismunicipais.com.br/a/rs/p/porto-alegre/lei-ordinaria/1988/616/6151/ lei-ordinaria-n-6151-1988-estabelece-o-plano-de-carreira-do-magisteriopublico-municipal-dispoe-sobre-o-respectivo-plano-de-pagamento-e-da-outras-providencias?q=6151 $>$. Acesso em: 08/02/2017. 
Decreto $\mathbf{n}^{\mathbf{0}} \mathbf{1 4 . 5 2 1}, 1^{\circ}$ de abril de 2004. Disponível em:<http://www2. portoalegre.rs.gov.br/cgibin $/$ nphbrs?s1 $=000026201$. DOCN.\&l=20\&u=\%2Fne tahtml $\% 2$ Fsirel $\% 2 F$ simples.html\&p=1\&r=1\&f=G\&d=atos\&SECT1=TEXT $>$. Acesso em: 08/02/2017.

PORTO VELHO. Lei $\mathbf{n}^{\mathbf{o}} \mathbf{3 6 0}$ de 04 de setembro de 2009. Disponível em: $<$ http://arquivos.portovelho.ro.gov.br/uploads/docman/lc_360_2009_com_ alteracoes_feitas_pelas_lc_n._370,_n._386.pdf>. Acesso em: 06/01/2017.

RANCIÈRE, Jacques. O mestre ignorante: cinco lições sobre emancipação intelectual. $2^{\mathrm{a}}$ ed. Belo Horizonte: Autêntica, 2005.

RECIFE. Lei $\mathbf{n}^{\mathbf{o}} \mathbf{1 6 . 9 9 2}$ de 27 de maio de 2004. Disponível em: <https:// leismunicipais.com.br/a/pe/r/recife/lei-ordinaria/2004/1700/16992/ lei-ordinaria-n-16992-2004-introduz-alteracoes-na-lei-municipal-n16520-99-que-cria-o-plano-de-cargos-carreira-e-remuneracao-do-grupoocupacional-magisterio-pccr-com-as-mudancas-que-lhe-foram-impostas-pelasleis-n-16556-00-n-16726-01-n-16796-02-e-n-16804-02?q=16.992-2004>. Acesso em: 06/01/2017.

RIO BRANCO. Lei $\mathbf{n}^{\mathbf{o}} 1892$ de 03 de abril de 2012. Disponível em: <http:// rbprev.pmrb.ac.gov.br/documentos/1892_de_03-04-2012_PCCR.pdf >. Acesso em: 05/01/2017.

. Lei $\mathbf{n}^{\mathbf{0}} \mathbf{1 7 9 5}$ de 30 de dezembro de 2009. Arts, 24, 25 e 26. https:// leismunicipais.com.br/plano-de-cargos-e-carreiras-rio-branco-ac Acesso em: 05/01/2017.

RIO DE JANEIRO (capital). Lei $\mathbf{n}^{\mathbf{o}} \mathbf{5 6 2 3}$ de $1^{\circ}$ de outubro de 2013. Disponível em: <http://www.rio.rj.gov.br/documents/10136/4410020/Lei_5623.pdf>. Acesso em: 06/01/2017.

SALVADOR. Lei $\mathbf{n}^{\mathbf{0}} \mathbf{2 6 . 1 6 8}$ de junho de 2015. Disponível em: <https:// leismunicipais.com.br/a/ba/s/salvador/decreto/2015/2617/26168/decreto-n26168-2015-regulamenta-a-lei-n-8722-publicada-em-22-dezembro-de-2014-quedispoe-sobre-o-plano-de-carreira-e-remuneracao-dos-servidores-da-educacaodo-municipio-de-salvador-e-da-outras-providencias?q=26.168>. Acesso em: 05/01/2017. 
SÃO LUIS. Lei $\mathbf{n}^{\mathbf{0}} 4931$ de 07 de abril de 2008. Disponível em: <https:// leismunicipais.com.br/a/ma/s/sao-luis/lei-ordinaria/2008/494/4931/leiordinaria-n-4931-2008-dispoe-sobre-o-plano-de-cargos-carreiras-e-vencimentodos-profissionais-do-magisterio-do-sistema-de-ensino-publico-da-prefeitura-desao-luis-e-da-outras-providencias>. Acesso em: 05/01/2017.

SÃO PAULO (capital). Lei 14.660, de 26 de dezembro de 2007. Disponível em:<http://www3.prefeitura.sp.gov.br/cadlem/secretarias/negocios_juridicos/ cadlem/integra.asp?alt $=27122007 \mathrm{~L} \% 20146600000>$. Acesso em: 07/01/2017.

SOUZA, Aparecida Neri de. Condições de trabalho na carreira docente: comparação Brasil-França. In: COSTA, Albertina de Oliveira; SORJ, Bila; BRUSCHINI, Cristina; HIRATA, Helena. Mercado de trabalho e gênero: comparações internacionais. Rio de Janeiro: Editora FGV, 2008.

SOUZA, Rosa Fátima de. Templos de civilização: a implantação da escola primária graduada no estado de São Paulo (1890-1910). São Paulo: Editora Unesp, 1998.

TERESINA. Portaria no 481, de 30 de agosto de 2013. Disponível em: http:/ / www.portalpmt.teresina.pi.gov.br/admin/upload/documentos/e1433a3735. pdf>. Acesso em: 07/01/2017.

VITÓRIA. Lei no 6754 de 16 de novembro de 2006. Disponível em: <http:/ / sistemas.vitoria.es.gov.br/webleis/Arquivos/2006/L6754.PDF>. Acesso em: 05/01/2017.

\footnotetext{
MÁRCIA APARECIDA JACOMINI é Doutora em Educação pela Faculdade de Educação da Universidade de São Paulo, Pós-doutora pela Faculdade de Educação da Universidade de São Paulo (2017-2018), com estágio na Fondazione Istituto Gramsci, Roma, Itália. Graduada em Pedagogia com especialização em psicopedagogia pela PUC-SP. Professora de graduação e pós-graduação do Departamento de Educação da Escola de Filosofia, Letras e Ciências Humanas da Universidade Federal de São Paulo (Unifesp) - Campus Guarulhos. Desenvolve pesquisa em Políticas Públicas para Educação e Gestão Educacional. Coordena o Grupo de Estudo e Pesquisa em Política Educacional e Gestão Escolar (Geppege). Membro do Conselho Editorial da Revista Fineduca. Secretária da Associação Nacional de Pesquisa em Financiamento da Educação (Fineduca) (2017-2019). Participa da Rede Escola Pública e Universidade (REPU) e do Núcleo de Estudos Intercampi em Políticas Públicas da Unifesp (Neipp-Unifesp). E-mail: jacominimarcia@gmail.com
} 
JUCA GIL é Pedagogo (1996), Mestre (2000) e Doutor (2007) em Educação pela Faculdade de Educação da Universidade de São Paulo (FEUSP), tendo realizado estágio de Doutorado Sanduíche junto à Université Lille III, na França (2006). Atualmente é Professor da Faculdade de Educação da Universidade Federal do Rio Grande do Sul (UFRGS). Pesquisa sobre políticas educacionais participando, no momento, da investigação nacional "Remuneração de professores de escolas públicas de educação básica no contexto do FUNDEB e do PSPN”, financiada pela CAPES, e do projeto "Estudo comparado de políticas públicas educacionais nacionais da Argentina, Brasil e Uruguai", financiado pelo CNPq. Foi editor de FINEDUCA - Revista de Financiamento da Educação, sendo membro de seu Comitê Editorial. É Diretor da Associação Nacional de Política e Administração da Educação (ANPAE) / RS e Vice-Presidente da Seção Sindical do ANDES na UFRGS. E-mail: jucagil7@gmail.com

EDIMÁRIA CARVALHO DE CASTRO é Licenciada em Pedagogia pela Universidade Federal de São Paulo (2017). E-mail: edimaria_castro@hotmail.com

Recebido em maio de 2018

Aprovado em julbo de 2018 